\title{
LBP rs2232618 polymorphism contributes to risk of sepsis after trauma
}

\author{
Hong-xiang Lu, Jian-hui Sun, Da-lin Wen, Juan Du, Ling Zeng, An-qiang Zhang* and Jian-xin Jiang*
}

\begin{abstract}
Background: Previous study revealed that rs2232618 polymorphism (Phe436Leu) within LBP gene is a functional variant and associated with susceptibility of sepsis in traumatic patients. Our aim was to confirm the reported association by enlarging the population sample size and perform a meta-analysis to find additional evidence.

Methods: Traumatic patients from Southwest $(n=1296)$ and Southeast $(n=445)$ of China were enrolled in our study. After genotyping, the relationship between rs2232618 and the risk of sepsis was analyzed. Furthermore, we proceeded with a comprehensive literature search and meta-analysis to determine whether the rs 2232618 polymorphism conferred susceptibility to sepsis.

Results: Significance correlation was observed between rs2232618 and risk of sepsis in Southwest patients ( $P=0.002$ for the dominant model, $P=0.006$ for the recessive model). The association was confirmed in Southeast cohort $\left(P=0.005\right.$ for the dominant model) and overall combined cohorts $\left(P=4.5 \times 10^{-4}, P=0.041\right.$ for the dominant and recessive model). Multiple logistical regression analyses suggested that rs2232618 polymorphism was related to higher risk of sepsis $(\mathrm{OR}=1.77,95 \% \mathrm{Cl}=1.26-2.48, P=0.001$ in Southwest patients; $\mathrm{OR}=2.11,95 \% \mathrm{Cl}=1.24-3.58$, $P=0.006$ in Southeast cohort; $\mathrm{OR}=1.54,95 \% \mathrm{Cl}=1.34-2.08, P=0.006$ in overall cohort). Furthermore, metaanalysis of four studies (including the present study) confirmed that rs2232618 within LBP increased the risk of sepsis $(\mathrm{OR}=1.75, P<0.001$ for the dominant model; $\mathrm{OR}=6.08, P=0.003$ for the recessive model; $\mathrm{OR}=2.72, P<0.001$ for the allelic model).
\end{abstract}

Conclusions: The results from our replication study and meta-analysis provided firm evidence that rs2232618T allele significantly increased the risk of sepsis.

Keywords: Trauma, Sepsis, Lipopolysaccharide-binding protein, Single nucleotide polymorphism, Meta-analysis

\section{Backgrounds}

According to WHO, $10 \%$ of deaths and $16 \%$ of disabilities around the world were due to traumatic injuries [1]. With the development of first aid and hospital treatment, the early mortality of major trauma patients declined in recent years [2]. However, the incidence of mortality caused by post-injury sepsis remained unchanged during the past decades $[3,4]$. Despite the obtained increasing research progress in sepsis after trauma, current knowledge about the molecular mechanisms of the development of sepsis is still limited [5]. Therefore, early diagnosis and treatment based on the

\footnotetext{
*Correspondence: zhanganqiang@126.com; hellojjx@126.com State Key Laboratory of Trauma, Burns and Combined Injury, Institute of Surgery Research, Daping Hospital, Third Military Medical University,
} Chongqing 400042, China

(c) The Author(s). 2018 Open Access This article is distributed under the terms of the Creative Commons Attribution 4.0 International License (http://creativecommons.org/licenses/by/4.0/), which permits unrestricted use, distribution, and reproduction in any medium, provided you give appropriate credit to the original author(s) and the source, provide a link to the Creative Commons license, and indicate if changes were made. The Creative Commons Public Domain Dedication waiver (http://creativecommons.org/publicdomain/zero/1.0/) applies to the data made available in this article, unless otherwise stated.

\section{perative requirements [6].}

Previous studies indicated that gene variants (generally single nucleotide polymorphisms, SNPs) in inflammatory response genes could contribute to different outcomes which are observed in sepsis and infectious diseases both in laboratory animal models and clinical patient cohorts $[7,8]$. Candidate gene studies for traumatic patients identified several SNPs in lipopolysaccharide-binding protein (LBP), toll-like receptor 1(TLR1), and tumor necrosis factor-alpha (TNF- $\alpha$ ) which were related to the development of sepsis [9-11]. The assessment of sepsis-specific genetic variants in these patients could explain the individual differences in susceptibility for trauma-related sepsis to some extent $[7,12]$. Therefore, those SNPs could serve as beneficial biomarkers to 
evaluate and monitor infection or inflammatory responses to trauma patients.

Lipopolysaccharide-binding protein (LBP), a key gene in the host innate immune response, has been reported to play a crucial role in the pathophysiologic process of sepsis after major traumatic injury [13]. We previously found that the rs2232618 (Phe436Leu) polymorphism in LBP had a significant association with the incidence of sepsis and MOD score in two non-dependent cohorts of major traumatic patients admitted from Chongqing (Southwest of China) and Zhejiang (Southeast of China). The correlation analysis showed these patients with variant $\mathrm{C}$ allele had higher sepsis morbidity risk and MOD score. Other studies also showed that rs2232618 could affect the outcome of sepsis patients [14, 15]. In addition, protein activities could enhance after $\mathrm{C}$ allele mutated to T allele at rs2232618 [16]. Thus, the current study was designed to examine the association between rs2232618 and sepsis after trauma by enlarging the sample size. Furthermore, a meta-analysis including previously published studies was carried out to provide a more precise estimate of this association.

\section{Materials and methods}

\section{Study populations}

Two unrelated study cohorts of traumatic injury patients in Southwest (Chongqing) and Southeast (Zhejiang) of China were performed for this study. Traumatic patients in the ICU at the Department of Trauma Surgery in the Daping Hospital and the Chongqing Emergency Medical Center were recruited during the period of between January 2005 and October 2016. The traumatic injury patients in the Second Affiliated Hospital, Zhejiang University, were enrolled between January 2008 and July 2015. The including criteria and excluding criteria were described previously [16]. Trauma severity of each person was assessed using the Injury Severity Score (ISS) (The Abbreviated Injury Scale: 2005 revisions) by two independent researchers. Demographic characteristics and clinical information were taken from the electronic medical record. Consequently, the diagnosis of sepsis was according to the criteria of the American College of Chest Physicians and Society of Critical Care Medicine Consensus Committee. Definition of infection was clinically positive bacterial cultures from blood, sputum, urine tissue, catheter tips, and wounds. For those trauma patients with multiple positive cultures, the first significant culture of gram-positive or gram-negative organisms occurring after admission was selected. Multiple organ dysfunction (MOD) score was the sum of single organ score calculated during every day the patients stayed in the hospital. The patient sampling and experiments got approval from the Institutional Ethics Review Board of the Third Military Medical University.
Informed consent for all subjects was acquired from the patients or their kin.

\section{Genotyping}

Blood samples of trauma patients were obtained immediately after admission by physicians or nurses. Total DNA of every patient was extracted from whole blood according to the laboratory protocol. Samples were stored at $-80{ }^{\circ} \mathrm{C}$ with a $40 \mu \mathrm{g} / \mathrm{ml}$ concentration. Pyrosequencing was utilized to genotype rs2232618 similar to our previous report $[16,17]$. The double-blind method was implemented. Approximately $10 \%$ of the samples was genotyped in duplicate to ensure genotyping quality.

\section{Statistical analysis}

Categorical data were shown as counts and percentages. Continuous data were given as means $\pm \mathrm{SD}$. Comparison of categorical data was conducted by $\chi^{2}$ analysis, and continuous data were analyzed using Student's $t$ test. Genotype frequencies were determined according to gene number. Hardy-Weinberg equilibrium (HWE) was assessed to detect whether the rs2232618 polymorphism distribution among the study population was stable by $X^{2}$ analyses. The correlation between rs 2232618 polymorphisms and the incidence of sepsis was performed by $\chi^{2}$ analyses in three genetic effects (allele dose genetic model, dominant genetic model, and recessive genetic model). Furthermore, the allelic odds ratio (OR) and $95 \%$ confidence intervals $(\mathrm{CI})$ were calculated by a multiple stepwise logistic regression analysis adjusted by identified confounding variables of age, sex, and ISS. Moreover, we also compared the MOD scores between different genotypes with Student's $t$ test. The exact $P$ values were considered significant if $P<0.05$. All statistical analyses were performed in SPSS 17.

\section{Meta-analysis of rs2232618 in association with sepsis risk} To confirm the involvement of rs2232618 in sepsis susceptibility, a meta-analysis combining published studies and our study was carried out. PubMed, Embase, and Web of Knowledge were searched in order to identify all published studies up to December 15, 2017, that had evaluated the associations between rs2232618 polymorphism and sepsis. Key words used for search were "rs2232618 or Leu436Pro" and "sepsis or severe sepsis or septic shock or septicemia." The inclusion criteria were as follows: (1) independent case-control or cohort study evaluating the association between rs2232618 and sepsis risk and (2) the number or frequency of genotypes was provided in detail or obtained by contacting the authors.

Information such as first author's name, publication year, country origin and the ethnicity of study population, genotype number, or allele frequency for case and 
control were collected from each study using a standardized data collection protocol. The odds ratio (OR) and its $95 \%$ confidence interval $(\mathrm{CI})$ were used to evaluate the strength of the association between rs2232618 and sepsis susceptibility based on genotype frequencies in cases and controls. The pooled ORs were performed for dominant (TT versus $\mathrm{CC}+\mathrm{CT}$ ), recessive $(\mathrm{TT}+\mathrm{CT}$ versus $\mathrm{CC}$ ), and allelic ( $\mathrm{T}$ versus $\mathrm{C}$ ) genetic models, respectively. The significance of pooled ORs was tested by $Z$ test $(P<0.05$ was considered statistically significant).

Between-study heterogeneity across all eligible comparisons was estimated by the Cochran's $Q$ statistic and the $I^{2}$ metric. Heterogeneity was considered significant at $P<0.05$ for the $Q$ statistic. For the $I^{2}$ metric, the following cut-off points were used: $I^{2}=0-25 \%$, no heterogeneity; $I^{2}=25-50 \%$, moderate heterogeneity; $I^{2}=50-$ $75 \%$, large heterogeneity; $I^{2}=75-100 \%$, extreme heterogeneity. A fixed-effects model, using Mantel-Haenszel method, was applied to pool data from studies when heterogeneity was negligible based on $P$ for $Q$ statistic greater than 0.1 ; otherwise, a random-effects model, using DerSimonian and Laird method was applied. The meta-analysis was conducted using Review Manager 5.0.

\section{Results}

Overall clinical characteristics of major traumatic patients There were1296 major traumatic patients from Southwest of China and 445 patients from Southeast of China enrolled and genotyped in our study. The demographic and clinical information of those patients was presented in Table 1. Most of the trauma patients were male. Patients were of young age (mean age $42.5 \pm 12.9$ and 41.4 \pm 12.3 ). All patients in the study survived more than $48 \mathrm{~h}$ after admitted to the hospital. Average ISS in Southwest and Southeast are 21.2 \pm 9.4 and $21.7 \pm 9.3$, respectively. Among them, incidence of trauma sepsis is $33.3 \%$ and $37.5 \%$ in the Southwest and Southeast of China, respectively. The main type of infection was respiratory tract infection in the two study cohorts $(27.6 \%$ and $43.1 \%)$. According to infection of bacterial species, gram-negative infections occupied about $41.4 \%$ and $38.9 \%$ and gram-positive infections were about $29.6 \%$ and $9.6 \%$. Among the trauma population, the mean of MOD score was $7.17 \pm 1.02$ and $6.41 \pm 0.85$ in Southwest and Southeast, respectively.

\section{Clinical correlation of the rs2232618with trauma-related sepsis}

The rs2232618 was successfully genotyped in 1296 Southwest of China trauma patients. The overall minor allele frequency $(\mathrm{MAF}=5.5 \%)$ was consistent with the 86 Chinese Han Beijing in HapMap datasets (MAF = 9.1\%). The genotype frequencies of rs2232618 was in line with Hardy-Weinberg equilibrium $(P=0.06)$
Table 1 Overall clinical characteristics of patients with major trauma

\begin{tabular}{|c|c|c|}
\hline Variables & $\begin{array}{l}\text { Southwest } \\
(n=1296)\end{array}$ & $\begin{array}{l}\text { Southeast } \\
(n=445)\end{array}$ \\
\hline Age, years & $42.5 \pm 12.9$ & $41.4 \pm 12.3$ \\
\hline Male/female, \% & $81.2 / 18.8$ & $77.8 / 22.2$ \\
\hline AlS max abdomen & $2.6 \pm 0.9$ & $2.5 \pm 0.6$ \\
\hline AIS max extremities/pelvis & $2.7 \pm 0.8$ & $2.8 \pm 0.5$ \\
\hline Als max face & $1.5 \pm 0.7$ & $1.7 \pm 0.3$ \\
\hline AIS max head/neck & $2.9 \pm 1.3$ & $2.5 \pm 1.1$ \\
\hline AIS max thorax & $3.1 \pm 0.6$ & $3.4 \pm 0.2$ \\
\hline ISS & $21.2 \pm 9.4$ & $21.7 \pm 9.3$ \\
\hline MOD scores & $7.17 \pm 1.02$ & $6.41 \pm 0.85$ \\
\hline Sepsis, $n(\%)$ & $432(33.3 \%)$ & $167(37.5 \%)$ \\
\hline \multicolumn{3}{|l|}{ Source of infection, $n(\%)$} \\
\hline Respiratory tract infection, $n(\%)$ & $70(27.6)$ & $72(43.1)$ \\
\hline Primary bloodstream infection, $n(\%)$ & $43(16.5)$ & $33(19.8)$ \\
\hline Urinary tract infection, $n(\%)$ & $24(9.2)$ & $20(12.0)$ \\
\hline Catheter associated infection, $n$ (\%) & $55(21.1)$ & $15(9.0)$ \\
\hline Wound infection, $n$ (\%) & $44(16.9)$ & $17(10.1)$ \\
\hline Others, $n(\%)$ & $18(6.8)$ & $9(6.0)$ \\
\hline \multicolumn{3}{|l|}{ Pathogens, $n$ (\%) (positive blood cultures) } \\
\hline Gram-negative, $n(\%)$ & $179(41.4)$ & $65(38.9)$ \\
\hline Gram-positive, $n$ (\%) & $128(29.6)$ & $16(9.6)$ \\
\hline Fungi, $n(\%)$ & $4(0.9)$ & $0(0)$ \\
\hline $\begin{array}{l}\text { Mixed gram-negative and } \\
\text { gram-positive, } n(\%)\end{array}$ & $5(1.2)$ & $0(0)$ \\
\hline Negative blood cultures, $n(\%)$ & $116(26.9)$ & $86(51.5)$ \\
\hline
\end{tabular}

(Table 2). Both allele and genotype frequencies of rs2232618 remained constant in the Southwest cohort. As presented in Table 3, no statistically significant difference in age, gender, or ISS was detected among traumatic patients with different genotypes. In the Southwest cohort, we found a strong association between rs2232618 and incidence of sepsis both in the dominant model $(P=0.002)$ and in recessive effect of the allele $(P=0.006)$, so the trauma patients with more $\mathrm{C}$ allele would be more likely to suffer from sepsis (TT $32.0 \%$, TC $43.9 \%$, CC $71.4 \%$ ). For multiple logistical regression analyses, data from allele dose model analyses adjusted by age, sex, and ISS also suggested that rs2232618 polymorphism had a significant correlation with higher morbidity rate of sepsis (OR $=1.77,95 \% \mathrm{CI}$ $=1.26-2.48, P=0.001$ ) (Table 3 ). In addition, when comparing the MOD score among patients with different genotypes, results indicated that $C$ carriers had a higher MOD score than the T carrier patients $\left(P=1.8 \times 10^{-6}\right.$ in case of dominant model) (Table 3). Therefore, $\mathrm{C}$ carriers may be more likely to have bad outcome. 
Table 2 Distribution of rs2232618 in the LBP gene among trauma patients in the two cohorts

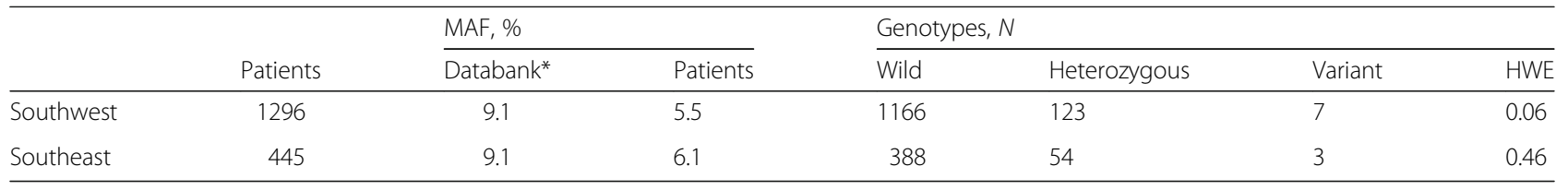

*Data were from HapMap database for Chinese Han Beijing $(n=139)$

We further validated those results in another distinct trauma cohort (Southeast of China). The characteristics and clinical data of injury patients from Southeast of China are shown in Table 1. The overall MAF of rs2232618 $(\mathrm{MAF}=6.1 \%)$ in the validation trauma cohort was consistent with those from Southwest of China and HapMap datasets. The genotype distribution conformed to the HWE $(P=0.46)$. As shown in Table 3, the risk rate of sepsis increased when the patients were with more $\mathrm{C}$ allele (TT 35.1\%, TC 53.75\%, CC 66.7\%). There was a strong association between rs2232618 and development of post-traumatic sepsis in the dominant effect $(P=0.005)$. However, relevance of rs2232618 and sepsis morbidity in recessive genetic model was not detected again; the reason might be that there were just three TT genotype trauma patients from Southeast of China and it was not enough to validate the significant association. A multiple analysis was performed by stepwise logistic regression; the results suggested that rs2232618 polymorphism was related to higher risk of sepsis $(\mathrm{OR}=2.11,95 \% \mathrm{CI}=1.24-3.58, P$ $=0.006)$. Furthermore, we found that the $\mathrm{C}$ carriers also had higher MOD score than those patients with $\mathrm{T}$ allele in the dominant model $(P=0.005)$ (Table 3$)$.

Due to no significant differences in the distribution of age, sex, and injury severity among patients from Southwest and Southeast of China were identified, the two cohorts were combined to enlarge the study cohort. Just as presented in Table 3, there was a stronger relevance between rs2232618 polymorphism and incidence of sepsis or MOD scores. The results suggested that $\mathrm{rs} 2232618 \mathrm{~T} \rightarrow \mathrm{C}$ would greatly increase the risk of sepsis in dominant and recessive model $\left(P=4.5 \times 10^{-4}\right.$ and $\left.P=0.041\right)$. Similar with previous results, allele dose effect analyses also confirmed the relevance for rs2232618 polymorphism and morbidity of sepsis $(\mathrm{OR}=1.54,95 \% \mathrm{CI}=1.34-2.08, P=0.005)$. Furthermore, a significant difference in MOD score was observed among traumatic patients with different genotypes $\left(P=1.4 \times 10^{-9}\right.$ in dominant genetic model).

\section{Results of meta-analysis}

Finally, three relevant articles were included in final meta-analysis [14-16]. There were 4 studies with 917 cases, and 1291 controls determined the association between rs2232618 polymorphism and sepsis risk (Table 4). However, Jabandziev's study [15] just provided genotype number for TT vs. TT + TC, so this study was just included in the dominant genetic model. Because Zeng et al.'s Chongqing and Zhejiang cohorts were included in our study, they were presented in study 1 and study 2 [16]. As shown in Figs. 1, 2, and 3, no significant

Table 3 Clinical relevance of rs2232618 among trauma patients in the two cohorts

\begin{tabular}{|c|c|c|c|c|c|c|c|}
\hline & Genotypes & $N$ & Age (years) & $\operatorname{Sex}(M / F, \%)$ & ISS & Sepsis, $n(\%)$ & MOD score \\
\hline \multirow[t]{4}{*}{ Southwest } & $\pi$ & 1166 & $42.6 \pm 12.8$ & $81.4 / 18.6$ & $20.8 \pm 9.3$ & $373(32.0)$ & $6.11 \pm 2.24$ \\
\hline & TC & 123 & $41.7 \pm 13.9$ & $77.2 / 22.8$ & $25.0 \pm 9.7$ & $54(43.9)$ & $7.20 \pm 2.23$ \\
\hline & CC & 7 & $43.0 \pm 10.7$ & $100 / 0$ & $24.1 \pm 13.2$ & $5(71.4)$ & $8.17 \pm 3.19$ \\
\hline & & & & & & $\mathrm{a} 1, \mathrm{~b} 1, \mathrm{cl}$ & $\mathrm{a} 2$ \\
\hline \multirow[t]{4}{*}{ Southeast } & $\pi$ & 388 & $41.3 \pm 12.2$ & $78.1 / 21.9$ & $21.5 \pm 9.3$ & $136(35.1)$ & $5.88 \pm 2.32$ \\
\hline & $\mathrm{TC}$ & 54 & $42.1 \pm 12.9$ & $79.6 / 20.4$ & $23.4 \pm 9.3$ & 29 (53.7) & $7.39 \pm 3.73$ \\
\hline & CC & 3 & $32.7 \pm 8.1$ & $33.3 / 66.7$ & $21.3 \pm 7.2$ & $2(66.7)$ & $6.00 \pm 1.41$ \\
\hline & & & & & & $a 3, c 2$ & $\mathrm{a} 4$ \\
\hline \multirow[t]{4}{*}{ Total } & $\pi$ & 1554 & $42.3 \pm 12.6$ & $80.6 / 19.4$ & $21.0 \pm 9.3$ & 509 (33.0) & $6.07 \pm 2.24$ \\
\hline & TC & 177 & $41.2 \pm 13.7$ & $92.1 / 7.9$ & $22.5 \pm 10.3$ & $83(46.9)$ & $7.27 \pm 2.87$ \\
\hline & CC & 10 & $43.4 \pm 12.1$ & $80.0 / 20.0$ & $23.8 \pm 11.9$ & $7(70.0)$ & $8.00 \pm 2.94$ \\
\hline & & & & & & $a 5, b 2, c 3$ & a6 \\
\hline
\end{tabular}

Dominant effect (variant homozygotes + heterozygotes vs. wild homozygotes) as analyzed by ANCOVA: ${ }^{\mathrm{a} 1} P=0.002,{ }^{\mathrm{a} 2} P=1.8 \mathrm{E}-6,{ }^{\mathrm{a} 3} P=0.002$,

${ }^{\mathrm{a} 4} P=0.005,{ }^{\mathrm{a} 5} P=4.5 \times 10^{-4},{ }^{\mathrm{a} 6} \mathrm{P}=1.4 \mathrm{E}-9$

Recessive effect (variant homozygotes vs. heterozygotes + wild homozygotes) as analyzed by ANCOVA: ${ }^{\mathrm{b} 1} P=0.032,{ }^{\mathrm{b} 2} P=0.041$

Allele dose association by logistic regression: ${ }^{\mathrm{c}} \mathrm{P}=0.001(\mathrm{OR}=1.77,95 \% \mathrm{Cl}=1.26-2.48),{ }^{\mathrm{C}} \mathrm{P}=0.006(\mathrm{OR}=2.11,95 \% \mathrm{Cl}=1.24-3.58),{ }^{\mathrm{C} 3} P=0.005(\mathrm{OR}=1.54$,

$95 \% \mathrm{Cl}=1.34-2.08$ ) 
Table 4 Characteristics of the studies included in the meta-analysis

\begin{tabular}{|c|c|c|c|c|c|c|c|c|c|}
\hline \multirow[t]{2}{*}{ Author } & \multirow[t]{2}{*}{ Country } & \multirow[t]{2}{*}{ Ethnicity } & \multirow{2}{*}{$\begin{array}{l}\text { Case/ } \\
\text { control }\end{array}$} & \multicolumn{3}{|l|}{ Case } & \multicolumn{3}{|c|}{ Control } \\
\hline & & & & $\overline{\pi T}$ & $\mathrm{TC}$ & $\overline{C C}$ & $\bar{\pi}$ & $\mathrm{TC}$ & $\overline{C C}$ \\
\hline Study $1^{\# 1}$ & China & Han & $432 / 864$ & 373 & 54 & 5 & 793 & 69 & 2 \\
\hline Study $2^{\# 2}$ & China & Han & $167 / 278$ & 136 & 29 & 2 & 252 & 25 & 1 \\
\hline Jabandziev 2014* & Czech & NA & $114 / 529$ & 85 & 29 & & 432 & 97 & \\
\hline Hubacek 2001 & Germany & NA & $204 / 250$ & 157 & 42 & 5 & 212 & 38 & 0 \\
\hline
\end{tabular}

Zeng's Chongqing and Zhejiang cohorts were included in our study, so they were not presented independently

${ }^{\# 1}$ Study1 represented the Southwest cohorts in our study

"2 Study2 represented Southeast cohorts in our study

*Jabandziev's study just provided genotype number for $\Pi \mathrm{T}$ v. $\Pi+\mathrm{TC}$. The number of $\Pi$ and CC was not shown separately. 29 and 97 represented the $\Pi+\mathrm{TC}$ in case and control, respectively

evidence of heterogeneity was observed in all genetic models (dominant model, $I^{2}=0, P=0.79$; recessive model $I^{2}=0, P=0.74$; allelic model $I^{2}=0, P=0.71$ ), so a fix-effects model was to pool the OR. In the dominant genetic model (TT VS. TC + CC), overall pooled OR for four studies combined was $1.75(95 \% \mathrm{CI}=1.40-2.19)(P<$ 0.001) (Fig. 1). Similarly, the recessive and allelic models were all significantly associated with sepsis risk (recessive genetic model $\mathrm{OR}=6.08,95 \% \mathrm{CI}=1.82-20.37, P=0.003$ (Fig. 2); allelic genetic model $\mathrm{OR}=2.72,95 \% \mathrm{CI}=2.13-$ 3.47, $P<0.001$ ) (Fig. 3).

\section{Discussion}

Patients after major traumatic injury were at high risk of sepsis and sepsis-associated multiple organ dysfunction syndrome [18, 19]. Therefore, increasing interest in identifying sepsis early in clinical management and providing timely and accurate therapies shorten hospital stays and improve overall outcomes [19]. Recently, researchers paid great attention to the potential action for genetic variation in sepsis susceptibility after traumatic injury. Various investigators had detected potential relevance between immune-related gene polymorphisms and risk of septic episodes [9]. SNPs could regulate the expression of innate immune system components, inflammatory cytokines, and coagulation cascade, so illuminating the influence of variation on immune inflammatory response from a cellular and molecular level might contribute to enhance management in the later stage of trauma $[15,20]$. Our study indicated that rs2232618 in LBP gene was associated with the morbidity of trauma-related sepsis and $\mathrm{C}$ allele carriers had higher sepsis rate in Southwest and Southwest of China trauma patients. Moreover, meta-analysis also revealed that rs2232618 was related with risk of sepsis under all genetic models.

LBP as a class I acute-phase protein of hepatic origin could mediate innate immune responses after recognizing lipopolysaccharides (LPS) originating from different gram-negative bacteria [21, 22]. LBP could form a high-affinity complex with LPS, then LPS was delivered to cell through CD14 or TLR4-MD2 and triggered a cascade of cytokines and pro-inflammatory mediators [23]. During sepsis, previous studies suggested that levels of serum LBP elevated almost seven times higher than normal levels [24]. Therefore, LBP might be a promising tool for the early clinical diagnosis of sepsis and appropriated in differentiating sepsis and systemic inflammatory response syndrome (SIRS) [25]. It was reasonable to suppose the SNP affecting the expression or activities of LBP might also have influence on individual susceptibility for sepsis. Flores et al. [26] have reported a common SNP risk haplotype of LBP gene that was strongly related to susceptibility to severe sepsis and mutant

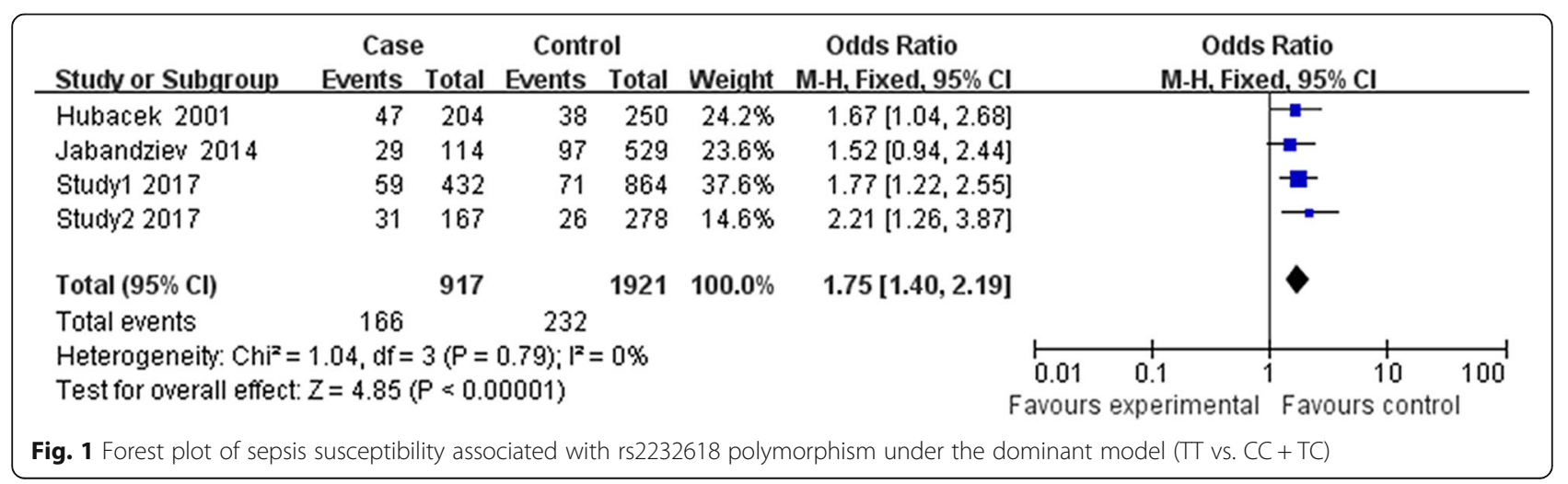




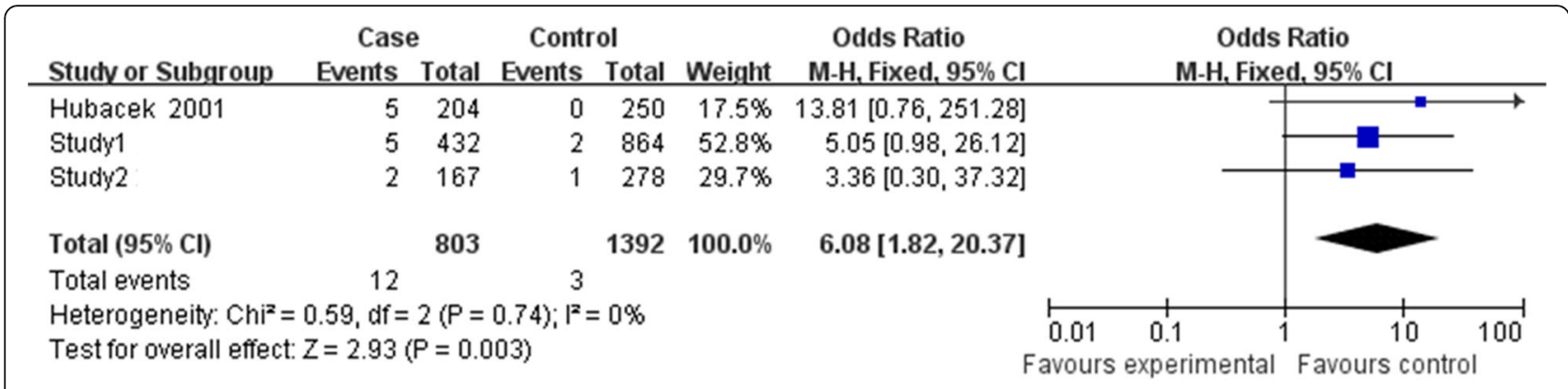

Fig. 2 Forest plot of sepsis susceptibility associated with rs2232618 polymorphism under the recessive model (TT + CT vs. CC)

homozygous individuals had increased risk of severe sepsis. Previous studies also reported that a frequent human LBP SNP (minor allelic frequency $=0.08$ ) affecting an amino acid led to a dysfunctional LBP and had a reduced binding capacity for LPS and lipopeptides. Decreased cytokine response after LPS exposure was also identified in variant carriers. Furthermore, retrospective trial evidence suggested that this LBP SNP was correlated with increased mortality rate during sepsis and pneumonia [27]. Therefore, LBP gene polymorphisms might have an association with sepsis susceptibility.

The $\mathrm{T} \rightarrow \mathrm{C}$ variant in rs2232618 polymorphism leaded phenylalanine transformation leucine at amino acid 436 (Phe436Leu) in the LBP protein [28]. Therefore, rs2232618 may influence interaction for LPS and CD14. Our previous investigation reported that rs2232618C allele carriers had higher sepsis morbidity and MOD score. Mechanism research suggested rs2232618 was also related to LPS-induced activation of peripheral blood leukocytes in patients with major traumatic injury, and the rs2232618 polymorphism had impact on activities of LBP protein, but not the production of LBP protein [16]. Furthermore, Hubacek et al. showed patients which were homozygote for Phe436Leu alleles exclusively had higher mortality after sepsis [14]. Jabandziev et al. reported combing rs2232618 in LBP with additional four SNPs could be used as a predictor of sepsis outcome in children [15]. Therefore, we concluded the rs2232618 was a functional variation and might play an important role in the pathophysiologic process of sepsis and MODS. In order to further investigate the clinical association between rs2232618 and risk of sepsis in larger major traumatic patient cohorts, we enlarged the sample size in the Southwest and Southeast of China. Similar to our previous findings, individuals with more C genotype for rs2232618 polymorphism had higher incidence of sepsis in both study populations. The following meta-analysis further confirmed the association. Thus, the results presented here indicated the rs 2232618 polymorphism might be a functional risk variant for sepsis in patients with major traumatic injury.

However, our study had several limitations. Firstly, owing to the lower incidence of gram-positive or mixed-infected sepsis, sub-group analysis between rs 2232618 polymorphism and trauma-related sepsis was not completed. Secondly, the diagnosis criterion of sepsis had been revised as sepsis-3 for patients who had a daily SOFA score $\geq 2$ with suspected infection in 2016 [29]. However, majority of our sepsis patients were diagnosed based on the sepsis- 2 for patients who met $\geq 2$ SIRS criteria with suspected infection, so whether the association would exist in patients identified by new sepsis criteria was unsure. Finally, we only recruited trauma patients in Chinese Han population, which is different from other ethnic populations in some aspects; further studies in other ethnic populations should be included to fully explore the association.

\begin{tabular}{|c|c|c|c|c|c|c|c|c|}
\hline Study or Subgroup & $\begin{array}{l}\text { Cas } \\
\text { Events }\end{array}$ & Total & Control & Total & Weight & $\begin{array}{c}\text { Odds Ratio } \\
\text { M-H, Fixed, } 95 \% \mathrm{Cl}\end{array}$ & \multicolumn{2}{|c|}{$\begin{array}{c}\text { Odds Ratio } \\
\text { M-H, Fixed, 95\% Cl }\end{array}$} \\
\hline Hubacek 2001 & 64 & 545 & 73 & 1728 & $43.3 \%$ & $3.02[2.12,4.28]$ & & 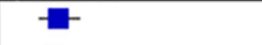 \\
\hline Study1 & 33 & 277 & 27 & 556 & $22.2 \%$ & $2.65[1.56,4.51]$ & & $\rightarrow-$ \\
\hline Study2 & 52 & 317 & 38 & 500 & $34.5 \%$ & $2.39[1.53,3.72]$ & & -6 \\
\hline Total $(95 \% \mathrm{Cl})$ & & 1139 & & 2784 & $100.0 \%$ & $2.72[2.13,3.47]$ & & $\gamma$ \\
\hline Total events & 149 & & 138 & & & & & \\
\hline $\begin{array}{l}\text { Heterogeneity: } \mathrm{Chi}^{2}= \\
\text { Test for overall effect }\end{array}$ & $\begin{array}{l}0.68, \mathrm{df}= \\
Z=7.98\end{array}$ & $\begin{array}{l}2(P= \\
P<0.0\end{array}$ & $\begin{array}{l}0.71) ;\left.\right|^{2}= \\
0001)\end{array}$ & $=0 \%$ & & & $\begin{array}{ccc}0.01 & 0.1 & 1 \\
\text { avours } & \text { experimental }\end{array}$ & ${ }_{\text {Favours control }}^{10} 100$ \\
\hline
\end{tabular}

Fig. 3 Forest plot of sepsis susceptibility associated with rs2232618 polymorphism under the allelic model (T vs. C) 


\section{Conclusions}

In summary, our study enlarged the sample size to further define the clinical relation between rs2232618 and the incidence of sepsis after severe traumatic injury. The follow-up meta-analysis strongly clarified the significant association between rs2232618 and sepsis. Future studies would explore whether rs2232618 could improve early clinical therapeutic interventions in patients with sepsis.

\section{Abbreviations}

Cl: Confidence intervals; HWE: Hardy-Weinberg equilibrium; ISS: Injury Severity Score; LBP: Lipopolysaccharide-binding protein; LPS: Lipopolysaccharides; MAF: Minor allele frequency; MOD: Multiple organ dysfunction; OR: Odds ratio; SIRS: Systemic inflammatory response syndrome; SNP: Single nucleotide polymorphisms; TLR1: Toll-like receptor 1; TNFa: Tumor necrosis factor-alpha

\section{Acknowledgements}

The authors thank PhD Kan Zhu (University of California, Davis, USA) for the language correction throughout the manuscript. We also thank all the participants who participated in this study.

\section{Funding}

This work is supported by National Natural Science Foundation of China (81601677 and 81571892) and Medical Research Funding of PLA of China (AWS14C003 and 17QNP005).

\section{Availability of data and materials}

Data sharing is not applicable to this article as no datasets were generated or analyzed during the current study.

\section{Authors' contributions}

D-LW curated the data. LZ carried out the investigation. J-XJ administered the project and visualization. D-LW and JD contributed to the resources. J-HS contributed to the software. $\mathrm{H}-\mathrm{XL}$ and $\mathrm{A}-\mathrm{QZ}$ wrote the original draft. A-QZ wrote, reviewed, and edited the manuscript. All authors read and approved the final manuscript.

\section{Ethics approval and consent to participate}

The study protocol was approved by the Ethical and Protocol Review Committee of the Third Military Medical University (No.TMMU2012009). Informed consent was obtained from the patients or their next of kin.

\section{Consent for publication}

Not applicable

\section{Competing interests}

All authors declare that they have no competing interests.

\section{Publisher's Note}

Springer Nature remains neutral with regard to jurisdictional claims in published maps and institutional affiliations.

Received: 11 October 2018 Accepted: 1 November 2018

Published online: 16 November 2018

\section{References}

1. Lord JM, Midwinter MJ, Chen YF, Belli A, Brohi K, Kovacs EJ, Koenderman L, Kubes $P$, Lilford RJ. The systemic immune response to trauma: an overview of pathophysiology and treatment. Lancet. 2014;384(9952):1455-65.

2. Park JH, Choi SH, Yoon YH, Park SJ, Kim JY, Cho HJ. Risk factors for sepsis in Korean trauma patients. Eur J Trauma Emerg Surg. 2016:42(4):453-8.

3. Raju R. Immune and metabolic alterations following trauma and sepsis - an overview. Biochim Biophys Acta. 2017;1863(10 Pt B):2523-5.

4. Cabrera CP, Manson J, Shepherd JM, Torrance HD, Watson D, Longhi MP, Hoti M, Patel MB, O'Dwyer M, Nourshargh S, et al. Signatures of inflammation and impending multiple organ dysfunction in the hyperacute phase of trauma: a prospective cohort study. PLoS Med. 2017;14(7): e1002352.

5. Xiao W, Mindrinos MN, Seok J, Cuschieri J, Cuenca AG, Gao H, Hayden DL, Hennessy L, Moore EE, Minei JP, et al. A genomic storm in critically injured humans. J Exp Med. 2011;208(13):2581-90.

6. Eriksson J, Gidlof A, Eriksson M, Larsson E, Brattstrom O, Oldner A. Thioredoxin a novel biomarker of post-injury sepsis. Free Radic Biol Med. 2017;104:138-43.

7. Rautanen A, Mills TC, Gordon AC, Hutton P, Steffens M, Nuamah R, Chiche JD, Parks T, Chapman SJ, Davenport EE, et al. Genome-wide association study of survival from sepsis due to pneumonia: an observational cohort study. Lancet Respir Med. 2015;3(1):53-60.

8. Wurfel MM. Genetic insights into sepsis: what have we learned and how will it help? Curr Pharm Des. 2008;14(19):1900-11.

9. David VL, Ercisli MF, Rogobete AF, Boia ES, Horhat R, Nitu R, Diaconu MM, Pirtea L, Ciuca I, Horhat D, et al. Early prediction of sepsis incidence in critically ill patients using specific genetic polymorphisms. Biochem Genet. 2016;55(3):193-203.

10. Teuffel O, Ethier MC, Beyene J, Sung L. Association between tumor necrosis factor-alpha promoter -308 A/G polymorphism and susceptibility to sepsis and sepsis mortality: a systematic review and meta-analysis. Crit Care Med. 2010;38(1):276-82

11. Thompson CM, Holden TD, Rona G, Laxmanan B, Black RA, O'Keefe GE, Wurfel MM. Toll-like receptor 1 polymorphisms and associated outcomes in sepsis after traumatic injury: a candidate gene association study. Ann Surg. 2014;259(1):179-85.

12. Bronkhorst MW, Patka P, Van Lieshout EM. Effects of sequence variations in innate immune response genes on infectious outcome in trauma patients: a comprehensive review. Shock. 2015:44(5):390-6.

13. Cunningham SC, Malone DL, Bochicchio GV, Genuit T, Keledjian K, Tracy JK, Napolitano LM. Serum lipopolysaccharide-binding protein concentrations in trauma victims. Surg Infect. 2006;7(3):251-61.

14. Hubacek JA, Stuber F, Frohlich D, Book M, Wetegrove S, Ritter M, Rothe G, Schmitz G. Gene variants of the bactericidal/permeability increasing protein and lipopolysaccharide binding protein in sepsis patients: gender-specific genetic predisposition to sepsis. Crit Care Med. 2001;29(3):557-61.

15. Jabandziev P, Smerek M, Michalek J, Fedora M, Kosinova L, Hubacek JA, Michalek J. Multiple gene-to-gene interactions in children with sepsis: a combination of five gene variants predicts outcome of life-threatening sepsis. Crit Care. 2014;18(1):R1.

16. Zeng L, Gu W, Zhang AQ, Zhang M, Zhang LY, Du DY, Huang SN, Jiang JX. A functional variant of lipopolysaccharide binding protein predisposes to sepsis and organ dysfunction in patients with major trauma. Ann Surg. 2012;255(1):147-57.

17. Alderborn A, Kristofferson A, Hammerling U. Determination of singlenucleotide polymorphisms by real-time pyrophosphate DNA sequencing. Genome Res. 2000;10(8):1249-58.

18. Rittirsch D, Schoenborn V, Lindig S, Wanner E, Sprengel K, Gunkel S, Blaess M, Schaarschmidt B, Sailer P, Marsmann S, et al. An integrated clinicotranscriptomic approach identifies a central role of the Heme degradation pathway for septic complications after trauma. Ann Surg. 2016;264(6):112534.

19. Ciriello V, Gudipati S, Stavrou PZ, Kanakaris NK, Bellamy MC, Giannoudis PV. Biomarkers predicting sepsis in polytrauma patients: current evidence. Injury. 2013:44(12):1680-92.

20. Cornell TT, Wynn J, Shanley TP, Wheeler DS, Wong HR. Mechanisms and regulation of the gene-expression response to sepsis. Pediatrics. 2010;125(6): 1248-58.

21. Rietschel ET, Brade H, Holst O, Brade L, Muller-Loennies S, Mamat U, Zahringer U, Beckmann F, Seydel U, Brandenburg K, et al. Bacterial endotoxin: chemical constitution, biological recognition, host response, and immunological detoxification. Curr Top Microbiol Immunol. 1996;216:39-81.

22. Schumann RR, Kirschning CJ, Unbehaun A, Aberle HP, Knope HP, Lamping $\mathrm{N}$, Ulevitch RJ, Herrmann F. The lipopolysaccharide-binding protein is a secretory class 1 acute-phase protein whose gene is transcriptionally activated by APRF/STAT/3 and other cytokine-inducible nuclear proteins. Mol Cell Biol. 1996;16(7):3490-503.

23. Ryu JK, Kim SJ, Rah SH, Kang JI, Jung HE, Lee D, Lee HK, Lee JO, Park BS, Yoon TY, et al. Reconstruction of LPS transfer cascade reveals structural determinants within LBP, CD14, and TLR4-MD2 for efficient LPS recognition and transfer. Immunity. 2017;46(1):38-50. 
24. Chen KF, Chaou CH, Jiang JY, Yu HW, Meng YH, Tang WC, Wu CC. Diagnostic accuracy of lipopolysaccharide-binding protein as biomarker for sepsis in adult patients: a systematic review and meta-analysis. PLoS One. 2016:11(4):e0153188.

25. Garcia de Guadiana Romualdo L, Albaladejo Oton MD, Rebollo Acebes S, Esteban Torrella P, Hernando Holgado A, Jimenez Santos E, Jimenez Sanchez R, Orton Freire A. Diagnostic accuracy of lipopolysaccharidebinding protein for sepsis in patients with suspected infection in the emergency department. Ann Clin Biochem. 2017;55(1):143-8. https://doi. org/10.1177/0004563217694378.

26. Flores C, Perez-Mendez L, Maca-Meyer N, Muriel A, Espinosa E, Blanco J, Sanguesa R, Muros M, Garcia JG, Villar J, et al. A common haplotype of the LBP gene predisposes to severe sepsis. Crit Care Med. 2009;37(10):2759-66.

27. Eckert JK, Kim YJ, Kim JI, Gurtler K, Oh DY, Sur S, Lundvall L, Hamann L, van der Ploeg A, Pickkers P, et al. The crystal structure of lipopolysaccharide binding protein reveals the location of a frequent mutation that impairs innate immunity. Immunity. 2013;39(4):647-60.

28. Iovine N, Eastvold J, Elsbach P, Weiss JP, Gioannini TL. The carboxyl-terminal domain of closely related endotoxin-binding proteins determines the target of protein-lipopolysaccharide complexes. J Biol Chem. 2002;277(10):7970-8.

29. Singer M, Deutschman CS, Seymour CW, Shankar-Hari M, Annane D, Bauer M, Bellomo R, Bernard GR, Chiche JD, Coopersmith CM, et al. The third international consensus definitions for sepsis and septic shock (sepsis-3). Jama. 2016;315(8):801-10.

Ready to submit your research? Choose BMC and benefit from:

- fast, convenient online submission

- thorough peer review by experienced researchers in your field

- rapid publication on acceptance

- support for research data, including large and complex data types

- gold Open Access which fosters wider collaboration and increased citations

- maximum visibility for your research: over $100 \mathrm{M}$ website views per year

At BMC, research is always in progress.

Learn more biomedcentral.com/submissions 